\title{
Um ensaio sul-americano: as nossas primeiras aproximações das relações entre o Brasil e o Uruguai na década de 1930
}

\author{
Rafael Nascimento Gomes \\ Universidade de Brasília, Brasília, Brasil. \\ Email: rafaelnascimentogomes@gmail.com
}

\begin{abstract}
Resumo: ${ }^{1}$ Discorrer sobre as relações do Brasil com seus vizinhos é uma história necessária a ser feita. Com o objetivo de contribuir para essa história, apresentaremos as nossas primeiras aproximações acerca das relações entre o Brasil de Getúlio Vargas (1930-1945) e o Uruguai de Gabriel Terra (1931-1938). Pela sua situação geográfica, o Uruguai pensa e projeta o seu posicionamento externo em função de sua situação regional. Aqui, analisaremos as relações entre o Brasil e o Uruguai ao longo da década de 1930.

Palavras-chave: Relações Internacionais do Brasil, Uruguai, Relações Brasil-Uruguai, Integração na América Latina.
\end{abstract}

\section{Un ensayo sudamericano: nuestras primeras aproximaciones de las relaciones entre Brasil y Uruguay en la década de 1930}

Resumen: Discurrir sobre las relaciones de Brasil con sus vecinos es una historia que requiere ser hecha. Con el fin de contribuir a esta historia, vamos a presentar nuestros primeros planteamientos de las relaciones entre el Brasil de Getúlio Vargas (1930-1945) y el Uruguay de Gabriel Terra (1931-1938). Debido a su situación geográfica, Uruguay piensa y proyecta su posición externa en función de su situación regional. Aquí, se analizan las relaciones entre Brasil y Uruguay durante la década de 1930.

Palabras clave: Relaciones Internacionales entre Brasil y Uruguay, relaciones Brasil-Uruguay, Integración en América Latina.

\section{A South American rehearsal: our first approximations on the relationship between Brazil and Uruguay in the 1930's}

\footnotetext{
Abstract: Discuss Brazil's relationship with their neighbors is a history that needs to be undertaken. Aiming to contribute to this history, we will present our first approximations about the relations between the Brazil of Getúlio Vargas (1930-1945) and the Uruguay of Gabriel Terra (1931-1938). Due to its geographical situation, Uruguay thinks and projects its external positioning in the perspective of its regional situation. Here, we analyze the relationship between Brazil and Uruguay over the 1930s.
} 
Key words: International Relationship of Brazil and Uruguay, Brazil-Uruguay relations, Integration in Latin America.

\section{Introdução}

Ao nos depararmos com a estátua do patrono da diplomacia brasileira, o Barão do Rio Branco, no Archivo Histórico Diplomático de la República Oriental del Uruguay percebemos a importância e a necessidade de mais estudos e pesquisas de História das Relações Internacionais do Brasil, em especial com os seus vizinhos sul-americanos. Por sua vez, a História das Relações Internacionais do Uruguai é uma área de estudo muito restrita, quer por parte de historiadores uruguaios quer de outras nacionalidades.

Dessa forma, discorrer sobre as relações entre o Brasil e o Uruguai é uma história necessária a ser feita. Para tal, partimos da documentação diplomática brasileira e uruguaia, com o auxílio da pouca- mas boahistoriografia existente sobre o tema. Com isso, com o objetivo de contribuir para essa historiografia, assim como estimular novas análises e interpretações, apresentaremos aqui as nossas primeiras aproximações do estudo que estamos realizando no mestrado do PPGHIS-UnB acerca das relações entre o Brasil e o Uruguai, marcada pelos governos democráticos e ditatoriais de Gabriel Terra (1931-1938) e de Getúlio Vargas (1930-1945).

Do lado uruguaio, o governo democrático do colorado² Gabriel Terra durou apenas dois anos (1931-1933). Pois, em 31 de março de 1933, Terra deflagrou um golpe de Estado instalando uma ditadura que duraria até meados de 1938. Do lado brasileiro, a configuração política não foi muito diferente. Com a chamada Revolução de 1930, Vargas realizou um golpe de Estado e instaurou um Governo Provisório -com caráter discricionário- até meados de 1934, com a promulgação da Constituição. Três anos foi o tempo de vida da constituição. O Governo Constitucional (1934-1937) durou até novembro de 1937, quando houve um novo golpe de Estado orquestrado por Vargas. Era o início da Ditadura do Estado Novo.

\section{Da euforia do centenário à "revolução de 1930"}

Em 1930, o Uruguai viveu a euforia de seu centenário, comemorou o título de primeiro campeão mundial de futebol, além de ter observado os movimentos políticos golpistas de seus países vizinhos, tanto em setembro na Argentina, como em outubro no Brasil. Em síntese, meio a um mundo em crise- declínio do modelo liberal-democrático- que impactou fortemente a realidade uruguaia, dissiparam-se utopias diversas- desde "o país modelo" do reformismo radical até o retorno do modelo agroexportador defendido pelos ganaderos (criadores de gado). 
De toda forma, o Uruguai se internacionalizou com mais intensidade nesse período. Por exemplo, o Ministério das Relações Exteriores uruguaio ampliou o número de representações diplomáticas e consulares pelo globo. Nessa "internacionalização", houve uma escolha prévia também pela "regionalização”, pois, um país tal como o Uruguai, localizado entre dois grandes colossos, deve levar em consideração a sua condição geopolítica. Reflexo disso foi a elevação das legações da Argentina e do Brasil à categoria de embaixadas nessa mesma época. Essas eram as primeiras missões creditadas com categorias superiores estabelecidas para as classes diplomáticas. (OLIVEIRA, 1984: 191)

Em meados de julho de 1930, os uruguaios gritavam campeones em comemoração à conquista da Primeira Copa do Mundo de Futebol, sediada em Montevidéu. No entanto, os festejos do centenário e a vitória no Mundial não esconderam a situação de crise na América Latina, fosse econômica ou política.

Raúl Jacob, em Uruguay (1929-1938): depresión ganadera y desarrollo fabril, destaca que quando os efeitos da crise econômica estrutural de 1929 chegaram à América do Sul, o Uruguai já estava em crise. O país tinha investido em casas e automóveis; importado demais; já estava endividado. A moeda caiu. Impulsionar a indústria apresentava-se como a mais provável resposta para aquela situação. (Jacob, 1981: 9)

Por outro lado, Juan Oddone assinala, em Uruguay entre la depresión y la guerra (1929-1945), que a Grande Depressão não teve no Uruguai efeitos tão devastadores como nos demais países latino-americanos, como o caso brasileiro. (Oddone, 1990: 51-54) A balança comercial uruguaia de 1930, por exemplo, mesmo com a crise econômica, superou a balança de 1929 com incrementos nas exportações e baixa nas importações. As importações uruguaias eram principalmente de origens estadunidenses, britânicas, germânicas, argentinas e brasileiras. Já os principais compradores de produtos uruguaios eram: Grã Bretanha, Argentina, Alemanha, Estados Unidos e Brasil. (Nahum, 1996: 94)

No Brasil, o Governo Provisório de Getúlio Vargas, instalado em novembro de 1930, não teve problemas para ser reconhecido internacionalmente. (Cervo, 2002: 233) Amado Cervo defende que o chanceler Afrânio de Melo Franco, político e diplomata mineiro que ficou à frente do ministério até 1933, não promoveu significativas alterações de rumos na política exterior do Brasil. A principal diferença se deu por meio de reflexo do contexto histórico vivenciado. Pois, no decurso da década de 1930, as transformações econômicas e sociais levaram os detentores do poder a uma nova percepção do interesse nacional. Embora sem descurar dos interesses das exportações tradicionais, a política externa brasileira buscou formas de cooperação e barganhas voltadas para um interesse nacional compreendido de maneira mais abrangente que o período anterior, pois visava contemplar outros segmentos da sociedade. (Cervo, op. cit.: 234) 
Cervo destaca que no contexto regional, o Brasil adotou uma atitude de prestígio do pan-americanismo, ao lado da conciliação. Em 1930, por exemplo, Afrânio de Melo Franco ofereceu, com sucesso, os bons ofícios para o reatamento das relações diplomáticas entre Peru e Uruguai. Na questão da Letícia, entre Peru e Colômbia, e na Guerra do Chaco, entre Bolívia e Paraguai, a diplomacia brasileira desempenhou também papel conciliador. Decorrente disso, no Prata, as relações Brasil-Argentina caminharam bem nos aspectos comercial e diplomático. A rivalidade militar apresentou melhora na ascensão de Vargas até 1936-1937. (Cervo, op. cit.: 235-236)

O período compreendido entre 1935 e 1941 na história da política externa brasileira foi sintetizado por Gerson Moura como o de “equidistância pragmática”- isto é, uma diplomacia econômica com o propósito de acelerar o crescimento interno-, pelo fato de o Brasil ter procurado tirar proveito da disputa então existente entre os dois blocos de poder, vale dizer, Estados Unidos e Alemanha. Por outro lado, o Uruguai deixou logo claro o seu posicionamento favorável aos Estados Unidos, ainda que houvesse grupos simpatizantes do nazismo e da Alemanha. Em síntese, podemos dizer que entre 1930 e 1945, o governo de Vargas obteve êxitos reais com a nova política externa, a qual se transformou em um instrumento eficaz para a obtenção de insumos e condições de crescimento econômico, industrialização, créditos e financiamentos das exportações, além do grande projeto siderúrgico de Volta Redonda, inaugurado em 1943.

\section{Brasil e Uruguai: para além das fronteiras geográficas}

As relações entre o Uruguai e o Brasil transpassam as fronteiras geográficas. Gabriel Terra foi um exemplo de tantos outros uruguaios que tem suas raízes ou vínculos no Brasil. Gabriel Terra era filho de José Ladislao Terra (1835-1902), por sua vez, filho de brasileiros proprietários de um estabelecimento de campo no departamento de Florida. Ladislao estudou em São Paulo durante a sua juventude, onde obteve o título de advogado, conheceu e tornou-se amigo íntimo, parente e gerente do Barão de Mauá, grande empresário do Brasil Imperial. Em razão dessa amizade, Mauá tornouse o padrinho do jovem menino Gabriel Terra. (Terra, 1962: 19-27)

Com 30 anos de idade Terra ingressou na vida política; seguiu o caminho de seu pai, e logo aderiu ao Partido Colorado. Nesse partido, militou como batllista ${ }^{3}$. Foi o mais jovem financista da história do Parlamento uruguaio. (Terra, op. cit: 43) El Industrial Uruguayo, periódico com certo prestígio na época, relatou o dia em que Terra assumiu o cargo do Ministério de Instruções Públicas, Indústrias e Trabalho. Terra reconhecia, desde os tempos de ministro, o papel preponderante do setor agropecuário para a economía uruguaia : "No olvida el doctor Terra, que la industria no es el género de actividad que más estimula los gobiernos: según él, hay mucho para hacer en el sentido de nuestro mejoramiento por la explotación de la agricultura y de la ganadería. Dedicará a esta última, preferente atención, por ser la industria nacional por excelência”(Terra, op. cit.: 46-47). 
Em "Relações Internacionais da América Latina: velhos e novos paradigmas”, Amado Cervo defende que a década de 1930 inaugurou uma fase de transição de paradigmas nas relações internacionais da região. Do paradigma liberal-conservador ao paradigma nacional-desenvolvimentista, os países latino-americanos buscavam a sua inserção na "era da industrialização”. (Cervo, 2001: 17-19). No entanto, notamos que isso não ocorreu da mesma forma e com a mesma intensidade em toda a América Latina, pois o declínio do modelo agro-exportador não se deu de imediato. Vejamos o caso do Brasil e do Uruguai.

De toda forma, o discurso predominante na América Latina, após a crise de 1929, era o desenvolvimento econômico por meio da industrialização. E esse, foi o discurso, tanto de Getúlio Vargas como de Gabriel Terra, ao ascender ao poder. Gabriel Terra venceu as eleições disputadas de novembro de 1930 e foi nomeado presidente constitucional no dia $1^{\circ}$ de março de 1931 sucedendo o também colorado Juan Campisteguy. Dois anos mais tarde, no dia 31 de março de 1933, mediante um golpe de Estado, Terra eliminou o Consejo Nacional de Administración, que formava junto ao Presidente da República o sistema do Executivo dual e bicéfalo estabelecido pela Constituição de 1919, e instaurou um governo ditatorial que durou até meados de 1938.

No cenário brasileiro, Vargas governou o nosso país num largo espaço de tempo, inicialmente com tentativas democráticas, mas as vias autoritárias foram as predominantes, até a consolidação de sua ditadura do Estado Novo, em 1937. Terra, no Uruguai, paradoxalmente, implantou um regime conservador que multiplicou as iniciativas reformistas. Em outras palavras, após o golpe de estado de 31 de março de 1933, o Uruguai viveu um momento de mais continuidades do que mudanças em suas diretrizes políticas, tanto interna como externamente. Vejamos.

\section{O Brasil de Getúlio Vargas e o Uruguai de Gabriel Terra}

Para Raúl Jacob, a política externa uruguaia - que contou com a complacência do herrerismo e do riverismo ${ }^{4}$ - sofreu um significativo reordenamento nesse decênio: ao fazer concessões, melhorou substancialmente as relações com a Grã-Bretanha; enxergou a Alemanha nazista e la madre pátria ${ }^{5}$ Itália com certa simpatia; rompeu relações com a URSS e com o governo republicano da Espanha; e aproximou-se gradativamente dos Estados Unidos. (Jacob, 1981: 111-116) Em outras palavras, podemos dizer que a inserção internacional do Uruguai nesses anos oscilou entre a Europa e as Américas.

A balança comercial favorável de 1930 transformou-se em uma balança desfavorável de 6.949.342 pesos em 1931. (Nahum, 1996:199-228) Em 1931, portanto, o Uruguai sofreu alguns efeitos do crash de 1929. Nesse ano, o Uruguai importou principalmente dos Estados Unidos, Grã-Bretanha, Argentina e Brasil. E exportou principalmente para a Grã-Bretanha (cerca de 
35\% do total), Alemanha, Argentina, França, Itália e Estados Unidos (apenas 5\%). Percebemos que a falta de sintonia do comércio exterior uruguaio era clara, sobretudo no caso do Brasil e dos Estados Unidos. O Brasil praticamente não importava de seu vizinho platino; a taxa não ultrapassou $1 \%$ do total das exportações uruguaias em 1931. Esta situação levou o Uruguai a adotar a política de comprar de quem nos compra. Logo, o tipo de política comercial estimulada pela crise-em que barreiras alfandegárias eram combatidas mediante tratados bilaterais com mútuo reconhecimento de cláusulas favorecedoras-, tendeu a favorecer a posição britânica, o principal cliente do Uruguai. É dizer que um terço das exportações do Uruguai era direcionado para o mercado britânico, enquanto, o principal beneficiário das compras uruguaias eram os Estados Unidos. (Jacob, op. cit.: 113)

A queda mundial de preços continuou afetando a economia uruguaia, brasileira e latino-americana, historicamente, mercados abastecedores de matérias-primas da Europa e dos Estados Unidos. A carne e a lã correspondiam aproximadamente a 65\% das exportações do Uruguai. Com a diminuição e o desaparecimento de seus mercados devido a barreiras comerciais e medidas protecionistas, o Uruguai buscou meios alternativos; em outras palavras, buscou ajuda para recuperar-se através da negociação de acordos comerciais bilaterais. (Nahum, 1997: 194) Assim, percebe-se que o tema central da política externa uruguaia nesses anos girou em torno das exportações, ainda que houvesse a perspectiva de ampliação de novos setores da economia nacional.

O ano de 1934 foi de constantes esforços mais do que realizações na esfera econômica. O comércio exterior uruguaio teve um aumento. As importações uruguaias aumentaram de 38.333.624 pesos (valores oficiais) para 42.205.899 pesos; e as exportações de 42.171.956 pesos (valores de mercado) para 43.012.250 pesos. Das exportações uruguaias, 24 \% foram destinadas ao Reino Unido, enquanto a Alemanha absorveu 16\%; os Estados Unidos receberam 11\% e para a Argentina seguiram apenas 7\%. Quanto às importações, 19\% provinham do Reino Unido, e 11\% dos Estados Unidos, enquanto Alemanha, Argentina e União Soviética empatavam na terceira posição, com 8\%. (Nahum, op. cit.: 197)

Uma grande curiosidade desse momento esteve nas relações comerciais quase que imperceptíveis com o Brasil; nem sequer apresentava percentagem considerável. No entanto, no campo político a situação era outra. Em agosto desse mesmo ano, o Presidente Terra visitou o país vizinho em uma viagem relativamente longa. Isto é, ao longo de 1934, as relações do Brasil com o Uruguai foram amistosas, com preponderância do fator político, enquanto que as relações com a Argentina foram 'cordiais', mas com destaque para o fator econômico.

No plano econômico, o comércio exterior de 1936 obteve uma balança comercial favorável, mesmo com a queda das exportações. As importações tiveram um aumento de 10\% (65. 934.630), já as exportações mostraram uma 
queda de 6\% (90.299.635) em relação a 1935. As exportações para o Japão cresceram 288\% e as importações da Argentina caíram 30\% no mesmo período. Depois da União Soviética com 55\%, a Argentina foi o mercado que mais deixou de exportar para o Uruguai. Enquanto as importações da Argentina caíram, as importações do Brasil cresceram 14\%. Além disso, o Uruguai importou 20\% mais da Alemanha, 28 \% do Japão e 103 \% mais da Espanha. No entanto, cabe destacar que as exportações para o Brasil também caíram, e em 41\%. (NAHUM, 1997: 391-399)

Um aspecto significativo, em 1936, foi o número de acordos comerciais estabelecidos entre o Uruguai e vários países europeus durante a visita do Ministro da Fazenda César Charlone à Europa.

O batllismo teve um papel importante nessa aproximação. Durante as três primeiras décadas do século XX, o Uruguai buscou aproximar-se do governo norte-americano. ${ }^{6} \mathrm{O}$ país enxergava os norte-americanos como um escudo protetor contra as ameaças expansionistas de seus poderosos vizinhos e das pressões diplomáticas das potências europeias. (Rodríguez Ayçaguer, 1996: 47)

\section{De “algodão entre dois cristais” ao "fiel da balança”}

O termo "fiel da balança” (la aguja de la balanza) é aqui entendido como a atualização do termo proferido, ainda nos século XIX, pelo Lord Ponsonby, “algodão entre dois cristais”. Ponsonby se referiu à Banda Oriental como "algodão entre dois cristais" para descrever a importância daquele território (atual Uruguai) para pacificar o cenário regional platino, disputado historicamente entre Portugal e Espanha no período colonial, e por Brasil e Argentina ao longo do século XIX, face à consolidação de seus respectivos Estados Nacionais. Com efeito, sua posição geopolítica entre dois grandes colossos faz com que o Uruguai se preocupe com o que sucede nos territórios vizinhos, sobretudo pela facilidade de repercussão em seu território.

Durante o governo de Juan Campisteguy (1927-1931), o Uruguai ajustou o destino da sua dívida com o Brasil. Dito ajuste consistiu na suspensão do programa de obras previsto, quanto à instalação do instituto agrícola-pastoril na fronteira comum, destinando estes recursos à construção de uma ferrovia que unisse as cidades de Treinta y Tres com Rio Branco, o que parecia mais adequado ao comércio recíproco e mais proveitoso para a integração dos territórios e das comunicações.

Na descrição das personalidades uruguaias em destaque do informe britânico de $1^{\circ}$ de janeiro de 1932, o chanceler uruguaio Juan Carlos Blanco foi apresentado como o ponto fundamental do "fiel da balança” das relações do Uruguai com os seus grandes vizinhos. O informe assegurava que o seu principal esforço era manter as boas relações com a Argentina e o Brasil, cuja tradicional rivalidade tornava delicada a posição de seu país. 
De toda forma, os diplomatas ingleses interpretaram a curta visita do chanceler uruguaio ao Rio de Janeiro- onde recebeu uma homenagem do chanceler brasileiro- em meados de 1931 como uma intenção de persuasão do governo brasileiro para enviar delegados à Conferência Econômica proposta pelo ministro uruguaio. O Ministro Juan Carlos Blanco teve êxito ao induzir o governo brasileiro a aceitar Montevidéu como a cidade sede da conferência, que tinha como objetivo estabelecer um tratado entre os dois países. (Nahum, 1996: 13) O governo uruguaio confiou ao ministro Blanco a compra de uma grande quantidade de trigo que o Brasil tinha adquirido dos Estados Unidos em troca do café. Se o acordo de redução dos direitos aduaneiros para os seus respectivos bens foi um sucesso, o acordo acerca do contrabando de tabaco e álcool, realizado em grande escala desde o Brasil, foi um fracasso. A extensão da fronteira dificultava a fiscalização do contrabando pelos militares e funcionários aduaneiros, além do fato de que vários desses estavam envolvidos no mesmo.

A única conferência internacional sucedida em 1931 na capital uruguaia foi a Conferência Tripartite que contou com a participação da Argentina, do Brasil e do Uruguai. Mais uma vez, o Uruguai colocou-se como o 'fiel' da balança de poder na região. Os três países tinham a esperança de chegar a um mútuo e comum acordo sobre as tarifas e o intercâmbio de produto. (Nahum, 1996: 201) O Ministro Blanco afirmava desde o início do governo Terra que um assunto primordial de sua gestão na chancelaria seria realizar acordos comerciais com os seus grandes vizinhos, Brasil e Argentina. ${ }^{7}$ Assim, com esse fim a presidência da República iniciou a Conferência Econômica de Montevidéu, da qual surgiu o projeto de Tratado com o Brasil e a Conferência Tripartite para a defesa comum das carnes. O projeto de tratado foi remetido ao Conselho Nacional de Administração e com algumas modificações foi enviado de imediato ao governo brasileiro ${ }^{8}$.

\section{As relações medíocres com a Argentina}

Durante o ano de 1930, a região platina foi marcada pelas relações medíocres entre seus vizinhos. As relações entre Uruguai e Argentina foram apresentadas como tirantes nesse período. Henry Ketels ${ }^{9}$, ministro da Bélgica em Buenos Aires, assinalou a rivalidade histórica entre os vizinhos. (Nahum, 1998: 353-356.)

Na verdade, como lembrou o ministro belga, tratava-se de uma rivalidade histórica. Uma 'herança maldita' desde o período colonial; desde a luta dos portos entre as capitais platinas. Em julho de 1930, essa rivalidade recebeu alguns toques picantes através da Primeira Copa do Mundo de Futebol sediada em Montevidéu. Uruguai e Argentina mais uma vez entraram em campo de disputa, no entanto, desta vez no esporte. E em pleno ano de seu centenário, o Uruguai não fez feio; venceu a Argentina por 4 x 2 na final e consagrou-se o primeiro campeão do mundo de futebol. Por sua vez, intensificou a rivalidade latente existente nas mentalidades das sociedades argentina e uruguaia. 
Meses depois da Copa do Mundo, o General Uriburu aplicou um um golpe de estado em 06 de setembro de 1930 . O governo provisório instaurado rapidamente reprimiu os anarquistas e os comunistas. Muitos desses chamados ‘subversivos’ refugiaram-se em Montevidéu. Diziam os golpistas argentinos: "al hacer desembarcar esos elementos tan deseables, y apenas pisaron tierra, fueron puestos en libertad”. (Nahum, op. cit.: 354)

Entre os refugiados na capital uruguaia estava o ex-ministro das Relações Exteriores, Horacio Oyhanarte. Oyhanarte era acusado de pequenos delitos civis e penais. Logo, Uriburu solicitou a extradição do antigo chanceler dentre outros. No entanto, as autoridades uruguaias recusaram o pedido de extradição justificando que se tratava de um jogo político do governo argentino. A Argentina não esperou para reagir.

O ministro do Interior uruguaio percebeu o perigo que essa política de 'portas abertas' poderia acarretar ao seu país. Além disso, Montevidéu era acusada pelos britânicos como o ponto de partida de incursões opositoras armadas para o território vizinho.$^{10}$ Diziam: “[...]tal simpatía manifestada en Montevideo es muy natural, dado que todos los cortadores de garganta y rufianes de la Argentina se han refugiado aquí y cualquier criminal es tratado como un héroe público. Si a estos indeseables inmigrantes se agregan los representantes y empleados soviéticos del "Iuyamtorg", que fue expulsado de Buenos Aires y solicitó refugio aquí, no habría de extrañarse que la policía local esté muy ocupada con todo esto. Alguna prensa local ha estado clamando por poner freno a este flujo de indeseables, pero la sección comunista del partido "Colorado" se opone a tal medida.” (Nahum, 1996: 206-207)

Em resumo, a recusa da extradição do ex-ministro argentino e de outros refugiados pelas autoridades uruguaias provocou represálias da Argentina. Uma dessas medidas impostas foi o obstáculo aos turistas uruguaios naquele país. Até mesmo a taxa do consulado argentino para adquirir o visto aumentou em 20 dólares. (Nahum, op. cit.: 355)

Julho de 1932 foi outro momento de tensões nas relações entre o Uruguai e a Argentina. Enrique Arocena destaca que as sucessivas rupturas das relações diplomáticas entre os vizinhos platinos tiveram uma origem comum, isto é, a atividade de elementos subversivos em território vizinho. (Oliveira, 1984: 194)

O motivo não era diferente do ocorrido em 1930. Três oficiais argentinos: Toranzo, Pomar e Abalos exilaram-se em território uruguaio em 1932. Depois de quase dois meses do rompimento das relações diplomáticas, entre julho e setembro de 1932, Juan José de Amézaga, como agente confidencial, foi enviado a Buenos Aires para expressar o desejo do governo uruguaio de reatar as relações entre os países platinos. O Uruguai aceitou os critérios propostos pela Argentina, e logo em seguida, dois decretos simultâneos reativaram as embaixadas de Buenos Aires e de Montevidéu entregando-as aos seus respectivos titulares: José María Cantilo e Leonel Aguirre. 
Com o seu outro grande vizinho, o Uruguai teve uma relação muito diferente. A partir das divergências com a Argentina, o Brasil atendeu de modo singelo as suas relações com o Uruguai. Assim, notamos que, o "fiel da balança”, pelo peso histórico de sua rivalidade com Argentina, tendeu, nesses anos, para o lado verde-amarelo.

Logo no início de 1933, antes do golpe de 31 de março ${ }^{11}$, Juan Carlos Blanco deixou o cargo de Ministro das Relações Exteriores do Uruguai para ser Embaixador no Brasil. Alberto Mañé assumiu a pasta.

A VII Conferência Pan-Americana foi realizada em dezembro de 1933 na capital uruguaia. A Conferência de Montevidéu caracterizou-se pelo livrecambismo e pela queda gradual das barreiras contra o movimento internacional de serviços, mercadorias e capitais, pela negociação de amplos tratados bilaterais de reciprocidade, o que se repetiu na Conferência Comercial Pan-americana de Buenos Aires, dois anos mais tarde. Uma das conquistas mais transcendentais dos latino-americanos em Montevidéu foi o artigo $8^{\circ}$ da Convenção sobre direitos e deveres dos Estados. Nesse artigo, consagrou-se o princípio de soberania nacional, o princípio de que "nenhum Estado tem o direito de intervir nos assuntos internos nem externos de outro Estado. Outro princípio fundamental de direito interamericano - o da igualdade jurídica dos Estados- foi posto em pauta.

De toda forma, evidencia-se que as relações com o Brasil de Getúlio Vargas mereceram especial atenção da diplomacia terrista. Do lado brasileiro, Vargas também se esforçou para manter as relações amistosas. No telegrama enviado ao Presidente Gabriel Terra em 20 de julho de 1934, comunicando-lhe da posse do governo provisório após ser eleito pela Assembleia Constituinte, Vargas assegurou a Terra que estreitaria cada vez mais "as boas relações felizmente existentes” entre ambos os países. E como destacou Carlos Roberto da Rosa Rangel, os discursos antiliberais dos dois chefes de Estado facilitaram na convergência de interesses entre os seus governos. (Rangel, 2010: 22)

Em agosto de 1934, Terra realizou uma visita oficial ao Brasil. O presidente uruguaio permaneceu cerca de um mês na capital brasileira; por motivos de saúde, retornou somente no dia 17 de setembro daquele ano. (Nahum, 2001: 131) No ano seguinte, Vargas retribuiu a visita. A bordo do encouraçado São Paulo vindo de Buenos Aires, o presidente brasileiro desembarcou em território uruguaio em 30 de maio de 1935. Segundo os informes de diplomatas estrangeiros, havia bandeiras do Brasil e de Vargas por toda a cidade. Em homenagem ao presidente brasileiro, a estação de linha férrea Treinta y Tres- Rio Branco passou a chamar-se "Presidente Doctor Getúlio Vargas”. (Jacob, 1981: 112) Além da notável admiração da diplomacia uruguaia por Vargas, alguns partidos políticos uruguaios também o admiravam. O ministro espanhol, Carlos Malagarriga, exageradamente, comentou a visita de Vargas da seguinte maneira: "En la comitiva del “caudillo Vargas” [grifo nosso] estaba su señora y su hija, el Ministro de Relaciones Exteriores y altos jefes de la Administración Civil, del Ejército y de la 
Armada. [...] En el banquete oficial se pronunciaron los dos discursos de protocolo en que, se acentuó la posición que el Uruguay desde hace más de un siglo adoptó respecto del Brasil, de homenaje casi feudal, por evidentes aunque hoy meramente teóricas recelos para con la Argentina”. (Nahum, 2001: 166-169)

Além do banquete oficial, ergueram um monumento do Barão do Rio Branco, patrono da diplomacia brasileira, na Avenida Brasil e ainda cantaram os respectivos hinos nacionais. A visita do presidente brasileiro durou até 02 de junho. No último dia da visita, a festa oficial deu-se no Hipódromo de Maroñas com a corrida de cavalos. Este dia começou como festa e terminou de forma trágica. Bernardo Garcia, dirigente do partido nacionalista, atentou contra a vida do presidente Terra.

Com efeito, certa vez, o Uruguai foi comparado à Bélgica, pela sua atuação no plano internacional devido a uma série de fatores tais como: o seu pequeno tamanho territorial, a sua localização geográfica entre vizinhos poderosos, o seu temor latente por tal fato e o seu forte apego pelo direito internacional (pensado como único escudo dos fracos), além de certa dose de vaidade pelos seus respectivos sucessos sociais e culturais (Nahum, 1998: 8), ou ainda por terem as suas capitais como cidades sedes da integração econômica regional. Assim, muito bem utilizada pelo ministro belga Henry Ketels tal comparação explica muito bem o porquê do Uruguai ser visto nessa monografia como uma agulha da balança do cenário regional. Dois grandes rivais históricos em disputa pela supremacia na regiãoArgentina e Brasil- influenciam decisivamente a formulação da política externa uruguaia. Em outras palavras, o Uruguai é visto aqui, não somente como a Suíça da América tal como denominava o senso comum uruguaio da época, mas também como a Bélgica da América do Sul (Nahum, 1998: 208-211).

\section{Considerações finais: notas de pesquisa}

Guiado por necessidades econômicas e certas sintonias ideológicas, o Uruguai viveu, nessa época, a transição da área de influência britânica à área de influência norte-americana. Dessa forma, podemos dizer que, a inserção internacional do Uruguai nesses anos oscilou entre a Europa e a América. Em outras palavras, o Uruguai reconhecia a sua capacidade de envolvimento e influência nas relações internacionais, e disso, buscou aperfeiçoar as suas chances de projeção no cenário internacional, a partir de uma perspectiva realista. Isso se deu, em grande medida, pela sua atuação no cenário regional, sobretudo, a partir de suas relações com o Brasil. Em resumo, a política externa do terrismo foi muito pragmática. (Frega, 2010: 85-121).

Podemos apresentar, portanto, as nossas primeiras aproximações de nosso estudo acerca das relações entre o Brasil e o Uruguai ao longo da década de 1930. Esses países iniciaram um processo de aproximação política e econômica, a exemplo do acordo alfandegário de 1931, das visitas de Gabriel Terra em 1934 e de Getúlio Vargas ao Uruguai em 1935. Essa 
aproximação teve interesses econômicos imediatos - conciliados por acordos alfandegários e medidas de repressão ao contrabando- e também expressou a convergência política-ideológica quanto às práticas autoritárias e centralizadoras adotadas pelos dois governos que, mesmo ocorrendo em momentos e circunstâncias diferentes, não comprometeu a articulação diplomática e o apoio recíproco no controle e repressão aos grupos oposicionistas e dissidentes.

Dois grandes rivais históricos em disputa pela supremacia na regiãoArgentina e Brasil- influenciam decisivamente a formulação da política externa uruguaia. Em outras palavras, o estudo das relações entre o Brasil e o Uruguai pode nos ajudar a compreender melhor a inserção regional, por sua vez, internacional do Brasil e dos países à sua volta. 


\section{Notas}

${ }^{1}$ Esse trabalho- nossas primeiras aproximações da dissertação de mestrado que está sendo desenvolvida no Programa de Pós-Graduação em História da Universidade de Brasília (PPGHIS-UnB)- é fruto de parte da monografia final de curso de graduação na Universidade de Brasília (2013), Inserção Internacional do Uruguai de Gabriel Terra (1931-1938), orientada pelo professor Dr. Francisco Doratioto, que, por sua vez, é produto do intercâmbio acadêmico realizado na Facultad de Humanidades y Ciencias de la Educación, Universidad de la República , em Montevidéu (2012). Cabe aqui agradecer aos amigos, professores e historiadores uruguaios que tão bem me receberam durante a minha estadia em seu país. Em especial à minha co-orientadora Ana María Rodríguez Ayçaguer. Cabe ainda agradecer a CAPES, pela bolsa concedida, agora no mestrado.

${ }^{2}$ Tradicionalmente a política partidária uruguaia, naqueles tempos, se resumia em dois partidos: o Partido Colorado e o Partido Nacional (Blanco), ainda que houvesse uma grande variedade interna de grupos políticos em cada partido.

${ }^{3}$ Batllismo era o segmento mais expressivo do Partido Colorado no Uruguai. Seguia os princípios reformistas de José Batlle y Ordoñez, presidente duas vezes entre 19031907 e 1911-1915.

${ }^{4}$ Herrerismo e riverismo foram correntes políticas antagônicas no Uruguai. O herrerismo foi um movimento do Partido Blanco (Nacional) liderado por Luiz Alberto de Herrera. Já o riverismo foi um dentre vários grupos que compunham o Partido Colorado.

${ }^{5}$ Termo que alude à presença massiva de imigrantes italianos no Uruguai.

${ }^{6}$ Sobre a política externa uruguaia das primeiras décadas do século XX ver o trabalho de Dante Turcatti: El equilíbrio difícil: la política internacional del Batllismo.

${ }^{7}$ Boletín del Ministerio de las Relaciones Exteriores. Segunda Época, Ano I. Tomo II, numero 5. $1^{\circ}$. de Diciembre de 1932. Montevideo, Imprenta Militar, 1932.p.555.

${ }^{8}$ Boletín del Ministerio de las Relaciones Exteriores. Op. Cit.; p. 555.

${ }^{9}$ Cabe lembrar que Ketels foi o primeiro titular da representação belga no Uruguai em 1912, antes disso, havia somente uma legação do outro lado do Rio da Prata, em Buenos Aires.

${ }^{10}$ Os soviéticos encontraram terra fértil no Uruguai. Montevidéu, segundo os informes diplomáticos , converteu-se no Soviete diminuto das Américas e naquela época já era vista como o centro da propaganda comunista da América Latina; como a diretriz comunista da América do Sul. Os soviéticos fingiram desenvolver relações comerciais para na verdade, desenvolverem suas ambições revolucionárias na região, diziam os representantes estrangeiros.

${ }^{11}$ Segundo os informes ingleses, Blanco foi mais do que representar o seu país no Brasil. Terra necessitava de um homem de confiança no Rio de Janeiro para explicar a chamada "revolução" que se sucederia no território vizinho, isto é, a instauração da ditadura. 


\section{Fontes e Referências Bibliográficas}

\section{Fontes primárias}

Boletines del Ministerio de las Relaciones Exteriores. Tomos I, II, V y VI. Montevideo: Imprenta Militar. 1932-1938. Fundo: Ministério das Relações Exteriores do Archivo Histórico-Diplomático del Ministerio de Relaciones Exteriores del Uruguay

Nahum, Benjamin (1998), Informes diplomáticos de los representantes de Bélgica em el Uruguay. Tomo I: 1832-1946. Universidad de la República, Departamento de Publicaciones, Montevideo.

Ìdem (2001), Informes diplomáticos de los representantes de España en el Uruguay. Tomos II e III. Universidad de la República; Departamento de Publicaciones, 2001, Montevideo.

Ìdem (1996-1998), Informes diplomáticos de los representantes del Reino Unido en el Uruguay. Tomos V, VI, VII e VIII. Universidad de la República; Departamento de Publicaciones, Montevideo.

Rodríguez Ayçaguer, Ana María (1996), Selección de informes de los representantes diplomáticos de los Estados Unidos en el Uruguay. Tomo I: 19301933. Universidad de la República; Departamento de Publicaciones, Montevideo.

Seções Brasil e Argentina do Fundo: Ministério das Relações Exteriores do Archivo Histórico-Diplomático del Ministerio de Relaciones Exteriores del Uruguay.

\section{Bibliografia}

Caetano, Gerardo; Jacob, Raúl (1989-1991), El nacimiento del terrismo. (3 vols.) Ediciones de la Banda Oriental, Montevideo.

Cervo, Amado; Bueno, Clodoaldo (2002), História da Política Externa Brasileira. EdUnB, Brasília.

İdem (2001), Relações Interacionais da América Latina: velhos e novos paradigmas. IBRI, Brasília.

Cisneros, Andrés; Escudé, Carlos (directores) (2000), Historia de las Relaciones Exteriores Argentinas. Grupo Editor Latinoamericano. Disponível en: http://www.argentina-rree.com/historia_indice00.htm

Clemente, Isabel (2005), Política exterior del Uruguay, 1830-1995. Tendencias, problemas, actores y agendas. Documentos de Trabajo No. 69. Montevideo. 
Corsi, Francisco Luiz (2000), Estado Novo: Política externa e projeto nacional. Editora UNESP: FAPESP, São Paulo.

De Los Santos, Clarel (2011), El péndulo magnetizado: las relaciones de Uruguay con Brasil durante la II Guerra Mundial. Facultad de Humanidades y Ciencias de la Educación, Avances de Investigación, 2011, Montevideo. Disponível em: http://www.academia.edu/4416921/ Egresados_Historia_9\#

Doratioto, Francisco (2014), O Brasil no Rio da Prata. FUNAG; Brasília.

Frega, Ana; Rodriguez Ayçaguer, Ana María; [et all] (2011), Historia del Uruguay en el siglo XX: 1890-2005. Ediciones de la Banda Oriental, Montevideo.

Hilton, Stanley E. (1977), O Brasil e as grandes potências: 1930-1939. Os aspectos políticos da rivalidade comercial. Civilização Brasileira, Rio de Janeiro.

Jacob, Raúl (1983), El Uruguay de Terra. 1931-1938. Ediciones de la Banda Oriental, Montevideo,.

Ìdem (1981), Uruguay 1929-1938. Depresión ganadera y desarrollo fabril. FCU, Montevideo.

Martiñez, José Luciano.(1937), Gabriel Terra: el hombre, el político, el gobernante. (3 vols.) Montevideo.

Moura, Gerson (1980), Autonomia na dependência. A política externa brasileira de 1935 a 1942. Nova Fronteira, Rio de Janeiro.

Oddone, Juan Antonio (1990), El Uruguay entre la depresión y la guerra. 1929-1945. FCU/FHCE, Montevideo.

Oliveira, Enrique Arocena (1984), Evolución y apogeo de la diplomacia uruguaya. 1828-1948. Montevideo.

Pérez Antón, Romeo (2010), Política exterior uruguaya del siglo XX. Ediciones de la Plaza, Montevideo.

Rangel, Carlos da Rosa (2010), O anti-liberalismo nos discursos de Gabriel Terra e Getúlio Vargas (1930-1938). Disponível em: http://www.fee.tche.br/ sitefee/download/jornadas/2/h2-04.pdf Acesso em julho de 2012.

Real de Azúa, Carlos (1959), "Política internacional e ideologías en el Uruguay”. En: Escritos. Montevideo, ARCA, 1989. Marcha, Montevideo, 3 de Julio de 1959. 
Polis, Revista Latinoamericana, Volumen 13, $N^{\circ}$ 38, 2014

Rodríguez Ayçaguer, Ana María (2009), Un pequeño lugar bajo el Sol. Ediciones de la Banda Oriental, Montevideo.

Ìdem (2008), La diplomacia del anticomunismo: la influencia del gobierno de Getulio Vargas en la interrupción de las relaciones diplomáticas de Uruguay con la URSS en diciembre de 1935. Estudos Ibero-Americanos, Vol. XXXIV, Núm. 1, junio, 2008, pp. 92-120. Pontifícia Universidade Católica do Rio Grande do Sul, Brasil.

Terra, Gabriel (hijo) (1962), Gabriel Terra y la verdad histórica. Montevideo.

Turcatti, Dante (1981), El equilibrio difícil: la política internacional del Batllismo. ARCA- CLAEH, Montevideo.

$$
* * *
$$

Recibido: 08.10.2014

Aceptado: 20.11.2014 